\title{
El proyecto de convento para mestizas de Santa Rosa de Lima, en Filipinas
}

\author{
Marta M. ${ }^{a}$ Manchado López. \\ Dpto. de Historia Moderna, Contemporánea y de América \\ Universidad de Córdoba
}

Este trabajo trata del proyecto de fundación de un convento para jóvenes mestizas de chino, patrocinado por los gremios de mestizos de tres pueblos próximos a Manila: Tondo, Binondo y Santa Cruz. Se ha realizado a partir de documentación inédita del Archivo General de Indias de Sevilla y se desarrolla entre los años de 1778 a 1789.

El proyecto, que llegó a contar con planos de construcción, tuvo que hacer frente a importantes dificultades como fue la oposición del arzobispo y la desidia del mandatario, que retrasó considerablemente los trámites precisos. En este trabajo se estudia el proceso seguido para conseguir la licencia que autorizara la fundación y las razones por las que ésta no se llegó a obtener, situando el tema en el particular contexto del archipiélago filipino.

\begin{abstract}
"Pero ¿para qué me canso, si sabemos que la mano de Dios no está ligada y que su estilo es revelar a los párvulos las cosas grandes que oculta a los sabios?".
\end{abstract}

\section{Introducción}

El presente estudio es continuación de una línea de trabajo centrada en el análisis del mundo de la espiritualidad femenina en el archipiélago filipino, a partir de dos de sus manifestaciones, los conventos y los beaterios. Este trabajo está dedicado al estudio del proyecto de fundación de un convento para jóvenes mestizas de chino, patrocinado por los gremios de mestizos de tres pueblos próximos a Manila: Tondo, Binondo y Santa Cruz. Se ha realizado a partir de documentación inédita del Archivo General de Indias de Sevilla y se refiere a los años 1778 a $1789 .{ }^{2}$

Los chinos constituían con respecto a los nativos de Filipinas una minoría insignificante, pero no así con respecto a los blancos, cuyo número fue siempre muy escaso y a los que igualaron e incluso superaron en algunas ocasiones. Como recoge el padrón hecho en abril de 1700, en Manila y en sus arrabales había 2.117 chinos. Éstos no eran los únicos residentes en las

1 AGI, Filipinas, 1048. Fray Bernardo Javier de las Alas, procurador de causas de la Audiencia de Manila, al real acuerdo, s.f.

2 Este trabajo se ha enriquecido con las referencias bibliográficas que me ha proporcionado la doctora Justina Sarabia Viejo, cuya gentileza agradezco desde estas páginas. 
islas, ya que había otros en las tierras del interior dedicados al comercio. En 1729, según un informe redactado por los propios chinos, el número total de los miembros de su comunidad existentes en Filipinas no pasaba de cinco mil. Unos años más tarde, en 1741, el oidor de la Audiencia de Manila, don Pedro Calderón Enríquez, calculaba que sólo en las provincias de Tondo y Cavite se contabilizaban unos cuatro mil chinos, a los que había que sumar los del parián de Manila, que en 1754, según el padrón mandado hacer por el gobernador don Pedro Manuel de Arandía, eran 1.181. Aunque este gobernador decretó la expulsión total de los chinos en 1755, siete años después había en el parián y en las provincias próximas a Manila 6.000 chinos. Las uniones de éstos con nativos fueron abundantes y en 1753 el número de mestizos de sangley se cifraba en $30.420 .^{3}$

Los españoles siempre miraron con suspicacia a los chinos, actitud que no comenzó a cambiar hasta la segunda mitad del siglo XVIII, cuando tuvieron que reconocer que la laboriosidad de esta comunidad podía ser de gran utilidad para el despegue económico de las islas. ${ }^{4}$ Dos eran las razones que alimentaron secularmente el recelo hacia los chinos o sangleyes: el hecho de que habían establecido un auténtico monopolio comercial en las transacciones al por menor y la perniciosa influencia que se les atribuía sobre la población indígena en lo relativo a prácticas religiosas. Ambas cuestiones se proyectaban igualmente sobre los chinos cristianos, a los que se contemplaba con desconfianza. ${ }^{5}$

\section{Los primeros momentos del proyecto}

La fundación de un convento en que pudiesen "consagrarse a Dios y apartarse de los peligros del siglo" las jóvenes mestizas de chino era la respuesta a un anhelo largamente acariciado por esta comunidad. El proyecto inició su andadura en el año 1778, cuando los mestizos de los pueblos de Tondo, Binondo y Santa Cruz firmaron un poder a favor de don José M. ${ }^{a}$

3 Díaz-Trechuelo, M.L.: "Filipinas", en Historia General de España y América, Madrid, 1983, Tomo XI-1, pág. 520.

4 Sobre este particular, véase Díaz-Trechuelo, M.L.: "Historia económica de Filipinas en la segunda mitad del siglo XVIII", en Cuadernos del Centro Cultural, Manila, 1978, págs. 20-22.

5 Describen perfectamente esta situación las siguientes palabras del arzobispo Basilio Sancho: "Los sangleyes perseveran todavía con conocido perjuicio de los naturales y ruina de nuestra Santa Fe. Varones de celo y conciencia me han representado ya la certeza de sus asambleas por la noche y predicación de la ley de Mahoma”. AGI, Filipinas, 1041. El arzobispo al rey. Manila, 4 de agosto de 1767. 
Mendoza y en su defecto de don Julián de Illescas (agentes de negocios y vecinos de Madrid) y en caso de falta de ambos, del padre dominico fray Sebastián Valverde, procurador general de la provincia del Santísimo Rosario de Filipinas. ${ }^{6}$ Éstos debían realizar los trámites y gestiones oportunos para conseguir la autorización que permitiera fundar el citado convento, conforme a las estipulaciones establecidas por los propios mestizos, plasmadas en unas instrucciones firmadas por éstos el 17 de diciembre del mismo año.

Según el texto de dichas instrucciones, las razones que sustentan la pretensión de los mestizos eran la existencia en la ciudad de Manila y en sus arrabales, e incluso en el resto del archipiélago, de un gran número de jóvenes mestizas que deseaban abrazar el estado religioso y la falta de un centro en el que pudieran satisfacer su vocación. En este documento se mencionan expresamente el convento franciscano de Santa Clara y el de dominicas de la tercera orden, de los que se dice que eran fundaciones reservadas a las españolas y mestizas de español exclusivamente.

En sentido estricto, a mediados del siglo XVIII había en las islas tan sólo un convento de religiosas, el de Santa Clara de Manila. Existían además los llamados beaterios, centros en los que vivían retiradas mujeres devotas y estaban en conexión con alguna orden religiosa que los tutelaba. La mayor parte de ellos en realidad tenían una doble naturaleza, ya que eran casas de retiro para mujeres piadosas y centros de enseñanza. Era frecuente que se profesaran votos, pero no siempre sucedía así. ${ }^{7}$ En esta categoría se

6 AGI, Filipinas, 1048. Manila, 9 de diciembre de 1778. Este poder es otorgado por los capitanes y principales de los pueblos de Tondo, Binondo y Santa Cruz. Ellos son: de Tondo, los capitanes don Miguel Antonio (gobernador de mestizos), don Juan Bautista, don Gaspar Cordero, don Domingo José, don José Gison, y los tenientes don Mariano de los Santos y don Francisco Balatbat. Los de Binondo: capitanes don Teodoro Ambrosio (gobernador de mestizos), don Francisco Ambrosio Soriano, don Miguel de los Santos, don Lucas del Rosario, don Domingo de la Cruz González, don Jacinto Ignacio Âlvarez y don Policarpio de los Reyes. Los de Santa Cruz: capitanes don Gregorio Alonso (gobernador de mestizos), don Julián de los Santos, don Tomás Mariano, don Bernabé Molina, don Mariano de los Reyes, don Julián de la Cruz y don Domingo Sarmiento, "Todos del gremio de mestizos, naturales y residentes de dichos pueblos". Los testigos fueron Manuel Guillermo, Juan Cayetano Flores y Francisco Bartolomé. El escribano "real y público de los del número de esta ciudad" fue Miguel Valencia. Tal y como consta expresamente en las instrucciones entregadas por los mestizos a sus apoderados, éstos debían actuar siempre de acuerdo con el padre fray Joaquín del Rosario, exprovincial de la orden de Santo Domingo que se había embarcado para Europa en 1778.

7 García de los Arcos, M.F.: Estado y clero en las Filipinas del siglo XVIII, México, 1988, págs. 100-104. Véase también Manchado López, M.M.a: "Religiosidad femenina y educación de la mujer indígena en Filipinas. El beaterio de la madre Paula de la Santísima Trinidad", en prensa, aparecerá publicado próximamente en la Revista de Indias. Sobre la historia del convento de Santa Clara, véase Pérez, L.: "Fundación del convento de Santa Clara de Manila y documentos a él pertenecientes", en Archivo Iberoamericano, núm. 52, Madrid, 1952, págs. 225-243. 
incluía el de Santa Catalina de Siena, fundado en 1696 por la madre Francisca del Espíritu Santo, natural de Manila, y por el padre fray Juan de Santo Domingo, provincial de la orden de predicadores. El fin primordial de esta fundación era la oración y la vida piadosa, pero al igual que sucedía con otras fundaciones parecidas, también admitía a jóvenes educandas. A mediados del siglo XVIII el centro contaba con cincuenta y cinco beatas, de las que quince eran españolas y el resto indias. ${ }^{8} \mathrm{El}$ hecho de que en los documentos se asimile este centro al convento citado puede responder muy probablemente a que en ambos se profesaban votos. En todo caso era evidente que no existía en Filipinas, en la época en que se pone en marcha el proyecto de las mestizas de sangley, un cauce adecuado que diera cumplida satisfacción a los deseos de sus hijas de ingresar en el estado religioso.

Según consta expresamente en las instrucciones entregadas a sus representantes, el proyecto respondía a los afanes de los mestizos de los tres pueblos citados de los extramuros de Manila. ${ }^{9}$ El convento sería de religiosas dominicas y llevaría por nombre Santa Rosa de Lima. Las madres fundadoras deberían venir, previa licencia, de conventos de Europa, "para establecer como se debe la observancia regular". Puesto que sería fundación de los mestizos de chino, en él debían profesar sólo las hijas y descendientes de mestizos de sangley con india, con exclusión de españolas o mestizas de español, criollas, indias puras, negras o cualquier "otra nación". En caso de existir un número de solicitudes de ingreso superior al de religiosas que se pudieran recibir, tendrían prioridad las naturales de los pueblos fundadores sobre las mestizas de otras localidades. Bajo estas condiciones, y especialmente la sujeción a la obediencia de los padres dominicos, los mestizos se comprometían a levantar el edificio con todas las dependencias precisas, una iglesia debidamente equipada y a dotarlo con una renta fija para la decente manutención de las religiosas. Éstas podrían llevar sus dotes y recibir las herencias que les pudiesen corresponder,

8 Díaz-Trechuelo, M. L.: Arquitectura española en Filipinas, 1565-1800, Sevilla, 1959, pág. 265. Precisamente a mediados del siglo XVIII el gobierno ordenó el traslado de las beatas al colegio de Santa Potenciana y la supresión de la fundación, pero ésta continuó su vida hasta el siglo XIX. Otros centros de igual naturaleza fueron el beaterio de la Compañía de Jesús (que tras la expulsión pasó a ser dirigido por el arzobispado), el de San Sebastián de Galumpang (agustinos recoletos), el de Santa Rita de Pásig (agustinos) y el de Santa Rosa o de la madre Paula (dominicos). Una aproximación al estudio de estos centros la encontramos en el trabajo de García de los Arcos, M.F.: "El convento de Santa Clara y los beaterios de Manila en el siglo XVIII", en El monacato femenino en el Imperio español. Memoria del II Congreso Internacional, México, 1995, págs. 225-237.

9 Es importante señalar que el término "mestizo" lo empleamos como sinónimo solamente de "mestizo de chino" o "mestizo de sangley". 
teniendo facultad para renunciarlas en favor del convento si lo deseasen. De esta forma, podría beneficiarse toda la comunidad de religiosas, cuyo número aumentaría o disminuiría en la misma proporción en que lo hicieran las rentas de que dispusiera el convento. Éste nunca recurriría a las limosnas ni al erario real para su sustento. Con ello se pretendía obtener más fácilmente la aprobación de un proyecto como éste, que no perjudicaría a otras fundaciones similares que se mantenían de la caridad pública o de las donaciones del Estado.

El empeño con que los mestizos pusieron en movimiento este asunto queda de manifiesto en dos hechos: en el rápido acopio de fondos y en los pasos seguidos para obtener la aprobación real de la fundación. En cuanto al primer aspecto señalado, en el momento de iniciarse los trámites precisos contaban ya con 12.000 pesos destinados a iniciar la construcción. Pero la recaudación de fondos continuaba y se afirmaba que, una vez conseguida la licencia real, "se juntaría caudal, no sólo suficiente, sino también superabundante" ${ }^{10}$ Sin embargo, no eran éstos los únicos fondos que la comunidad mestiza estaba dispuesta a comprometer en el proyecto y así hicieron llegar a varios comerciantes de Cádiz diez picos y veinticinco libras de pimienta negra "de buena calidad" y ciento ochenta y cuatro libras de ruibarbo superior, a fin de que el producto de su venta se remitiera a sus apoderados en Madrid. ${ }^{11}$

Había cierta impaciencia en la comunidad mestiza por conseguir la aprobación real. Para obtenerla autorizaban a sus apoderados a hacer los gastos que estimaran precisos. De ahí que manifiesten su deseo de obtener la licencia real absoluta, y de no ser así, que al menos se consiguiera un permiso para iniciar las obras, con la condición de que los mestizos dispusieran de los caudales suficientes para la construcción y dotación del monasterio. Para acelerar los trámites, se pediría al rey que nombrara a una persona de su satisfacción, encargada de declarar que tal requisito se cumplía para proceder sin más espera a dar inicio a la fundación. Esta misma persona debía tener también facultad para declarar el número de reli-

10 AGI, Filipinas, 1048. Instrucciones dadas por los gobernadores y principales de los gremios de mestizos de chino de los pueblos de Tondo, Binondo y Santa Cruz, a sus apoderados en Madrid, 17 de diciembre de 1778 .

11 Los comerciantes eran don Jacobo Galván, en primer lugar, don José Galván y Repun, en segundo lugar, y en su defecto, don Francisco de la Guardia, marqués de Castillejos. El "pico" es una unidad de peso de origen chino, equivalente a $63,262 \mathrm{kgs}$. en casi todo el archipiélago filipino. El ruibarbo es una planta herbácea de la familia de las poligonáceas, de usos variados aunque especialmente valorada en medicina como purgante. 
giosas que podían ser admitidas. En cualquier caso, se autorizaba a los apoderados a realizar toda diligencia conducente a obtener la licencia para el convento, aun alejándose de las propias instrucciones que se les había entregado, pero siempre que mediara el consejo "de abogados y otros sujetos inteligentes" y que la fundación fuera de dominicas de la segunda orden y para hijas y descendientes de mestizo de sangley e india.

Los trámites para la fundación del convento empezaron de la forma ya expuesta. Andando el tiempo, los mestizos supieron que habían violado la normativa establecida para estos casos por la ley e intentaron rectificar su error. ${ }^{12}$ Efectivamente, años más tarde, los nuevos gobernadorcillos de mestizos de los pueblos de Tondo, Binondo y Santa Cruz elevaron un escrito al gobernador de las islas pidiendo su intervención en este asunto. En realidad lo que demandaban no era sino el cumplimiento por parte de la suprema autoridad civil de las islas de aquella parte que le correspondía en razón del vicepatronazgo que ostentaba. Así, los mestizos pidieron que el gobernador informara de que su proyecto era perfectamente viable, que habían reunido ya 12.000 pesos y podían reunir más y que no perjudicaría a terceras personas. Solicitaban también que se fundamentase su pretensión en los servicios que dicha comunidad había prestado y continuaba prestando a la Corona y al bien público de las islas.

\section{La tramitación del expediente en Manila}

La petición de los mestizos fue remitida al fiscal de la Audiencia en febrero de 1780. Casi un año hubo de transcurrir antes de que su informe llegara a manos del gobernador, quien sometió el asunto también al parecer de su asesor. Ambos coincidieron en que, de acuerdo con la ley I, título 3, libro I de la Recopilación, se debía recabar la opinión del arzobispo y completar todos los trámites que la legislación ordenaba en estos

12 La ley 1, título III, libro I de la Recopilación, establecía que "en las ciudades y poblaciones de nuestras Indias se edifiquen y funden monasterios de religiosos, siendo necesarios para la conversión y enseñanza de los naturales y predicación del Santo Evangelio, con calidad de que antes de fabricar iglesia, convento ni hospicio de religiosos se nos dé cuenta y pida licencia especialmente, como se ha acostumbrado en nuestro Consejo de Indias, con el parecer y licencia del prelado diocesano, conforme al Santo Concilio de Trento, y del virrey, Audiencia del distrito, o gobernador, e información de que concurren tan urgente necesidad y justas causas, que verosímilmente puedan mover nuestro ánimo y quedar informado para lo que nos fuesemos servido de proveer". Recopilación de Leyes de los Reynos de las Indias. Edición facsimilar de la 4. ${ }^{a}$ impresión hecha en Madrid el año 1791, Madrid, 1943, T.I. 
casos..$^{13}$ Ocupaba por aquel entonces la sede metropolitana de Manila el enérgico escolapio don Basilio Sancho de Santa Justa y Rufina, quien se inhibió en esta cuestión considerando que, puesto que los mestizos habían iniciado directamente el trámite ante el soberano, no cabía más que esperar la decisión real sobre el tema. Con todo, no se mostró muy entusiasmado por el proyecto al que calificaba de innecesario:

"No hay duda que esta erección tiene un fin piadoso, pero también no aparece aquella necesidad que la mencionada ley llama urgente para erección de monasterios en las Indias. Y, considerado más de fondo el espíritu de esta ley, se requiere otras causas no menores que aquella necesidad. Nada más desea este prelado que el bien de las almas y el acierto en su dirección y en el real servicio a que siempre propenden mis conatos". ${ }^{14}$

Pasado el expediente a la Audiencia, ésta confirió comisión a don Emeterio Cacho, a la sazón oidor alcalde del crimen, para que recogiera los informes de las personalidades civiles y eclesiásticas prescritos por las leyes. En total se recibieron dieciocho testimonios entre los días 20 y 23 de marzo de 1781, de los que la mayor parte (12) correspondían a eclesiásticos. A todos los informantes se les preguntó acerca de cuatro cuestiones: si sabían de la existencia en la ciudad de Manila de algún convento o beaterio en el que se recibiese como religiosas a las mestizas de sangley; si tenían conocimiento de que alguna de ellas hubiese pretendido tomar hábitos y hubiese sido rechazada; si consideraban a los mestizos capaces de reunir los fondos precisos para levantar y mantener un convento y si dicha fundación causaría perjuicios a las comunidades religiosas o a la sociedad de las islas. En cuanto a los seis testimonios de civiles, todos ellos coincidieron en que no había en la capital convento alguno, excepción hecha del de Santa Clara y del Beaterio de Santa Catalina y que en ninguno de los dos se admitía a mestizas de sangley, circunstancia ésta que había que demos-

13 El informe del fiscal está fechado en Manila el 27 de enero de 1781. El 6 de febrero el gobernador pidió parecer al asesor, quien firmó su dictamen el 9 del mismo mes. Desempeñaba por entonces el cargo de capitán general y gobernador de las islas don José Basco y Vargas, quien había tomado posesión el 28 de julio de 1778, ocupando este puesto hasta el año 1787. Sobre los aspectos más significativos de su mandato, véase Buzeta, M. y Bravo, F.: Diccionario geográfico-estadísticohistórico de las islas Filipinas, Madrid, 1851, T.II, pág. 263.

14 AGI, Filipinas, 1.048. El arzobispo, Basilio Sancho de Santa Justa y Rufina, al gobernador. Manila, 17 de febrero de 1781, en "Testimonio de las diligencias practicadas conforme a ley en la pretensión de los mestizos de sangley de los pueblos de Tondo, Binondo y Santa Cruz para la fundación y fábrica de un monasterio de monjas del segundo orden de Santo Domingo, con el título de Santa Rosa de Lima", fols. 22v-23. En lo sucesivo citaré este expediente como "Testimonio". 
trar en las informaciones que se realizaban previamente a la admisión de las aspirantes. Eran frecuentes los casos de jóvenes que habían visto frustrados sus deseos de abrazar el estado religioso por dicha causa, a pesar de contar con caudales suficientes. De ahí que, en general, la fundación que pretendían los mestizos fuera bien recibida por los informantes, que veían en ella "el único medio para que se pierdan menos almas y se adelante en lo espiritual". ${ }^{15}$

La mitad de los declarantes consideró difícil que los mestizos reunieran los fondos necesarios para construir, dotar y mantener el convento. En realidad, ésta no era la opinión más común entre la sociedad española de las islas, que frecuentemente acusaba a aquéllos de enriquecerse con sus lucrativas actividades. Más en consonancia con este punto de vista se encuentra el testimonio de don Felipe Vélez Escalante, capitán de una de las compañías urbanas de Manila, quien aseguró que: "siempre que el gremio de mestizos se junte, podrán recoger el caudal que exige dicha erección y dotación, atento a que sólo ellos tienen al presente la mayor masa de plata" ${ }^{16}$ Sin embargo, era compartida por todos los informantes la convicción de que, de conseguir establecer el convento, no se perjudicaría a nadie, siempre que los mestizos respondieran unidos a la obligación de garantizar los fondos precisos para su sustento y no se recurriera a pedir limosna.

Los testimonios de personas eclesiásticas fueron recabados de las órdenes religiosas y de miembros del cabildo catedral. En cuanto a los primeros, se tomó declaración a dos religiosos de cada una de las órdenes existentes en las islas, previa licencia de sus superiores. ${ }^{17}$ Los miembros del cabildo catedral fueron el doctor don Miguel Cortés de Arredondo y Oriosolo, deán y el doctor don Antonio Fernández de Córdoba, canónigo de gracia. Sus informes coincidían únicamente en la afirmación de que no

15 Ibídem. Declaración jurada de don Juan Antonio Panelo, "regidor propietario del ayuntamiento, y su decano". Manila, 21 de marzo de 1781. "Testimonio", fol. 40. Tan solo un declarante, don Alberto Jacinto de Reyes, antiguo regidor decano, no consideraba útil dicha fundación, a pesar de que reconocía que las mestizas que quisieran tomar los hábitos no eran admitidas en convento alguno.

16 Ibídem. "Testimonio", fols. 46v-47.

17 Los religiosos que prestaron declaración fueron: fray José de Santa Orocia, procurador general de la provincia de San Nicolás, fray Vicente de San Agustín, prior del convento de San Nicolás, fray Francisco González, prior del convento de San Pablo, fray Andrés Patiño, lector en sagrada teología del convento de San Pablo, fray Diego Martín, prior del convento de Santo Domingo, fray Manuel de San José, predicador general de la provincia del Santísimo Rosario, fray Antonio Torres, presidente superior de la provincia de San Rafael, fray Ignacio Seares, religioso presbítero de la provincia de San Rafael y capellán del convento de San Juan de Dios, fray José Cortés, guardián del convento de San Francisco y fray Blas Ramiro, ministro del pueblo de Dilao y definidor de la provincia de San Francisco. 
eran admitidas las mestizas en el convento de Santa Clara, ni en el beaterio de Santa Catalina. En todo lo demás sus opiniones no pueden ser más opuestas. Así el deán afirma:

"Que los dichos mestizos de público y notorio son muy hábiles a buscar sus haberes, y que los contempla bien parados para la fundación de este monasterio y para las rentas de subsistencia que requieren las leyes de su majestad, y en cuanto al beneficio espiritual se siga de esta fundación, asegura que será grande y de mucha edificación no sólo para los de su nación, sino para todo el público, sin que se siga perjuicio alguno a éste (...) y de consiguiente ni a las otras comunidades que hay, siempre que tengan su dote competente y no hayan de mendigar". ${ }^{18}$

Frente a esta opinión, a juicio del doctor Fernández de Córdoba, los mestizos de sangley no disponían de caudal suficiente para la fundación y dotación y tampoco lo conseguirían reunir una vez obtenida la licencia real. Sin embargo, su opinión contraria a la erección del convento se fundamentaba también en razones de más trascendencia, ya que no consideraba "a las que provienen de su origen capaces en general para encargarse de la perfección que se requiere de la vida religiosa, y que de consiguiente, no lo considera útil a la causa pública ni al Estado". ${ }^{19}$

De las declaraciones recogidas a miembros de las órdenes religiosas e incorporadas al expediente se desprende que éstas eran conscientes de la frustración que la comunidad mestiza sentía al ser rechazadas las instancias de sus hijas para ingresar en los conventos de la ciudad. Dos de los religiosos informantes explicaban cómo habían realizado gestiones personalmente, a fin de lograr el ingreso de alguna joven mestiza, pero que finalmente vieron fracasar todos sus esfuerzos. Tal es el caso de fray José de Santa Orocia, procurador general de recoletos, a quien se le contestó que se cansaba en vano, "porque en teniendo sangre de sangley de ninguna suerte la recibirían". ${ }^{20}$ Por responder a una demanda muy sentida, el proyecto del convento fue positivamente valorado. Ejemplo son las palabras de fray Manuel de San José, predicador general de la provincia del Santísimo Rosario:

18 AGI, Filipinas, 1.048. Declaración jurada del doctor don Miguel Cortés de Arredondo y Oriosolo, deán de la catedral, 21 de marzo de 1781. "Testimonio", fols. 51-52.

19 Ibídem. Declaración jurada del doctor don Antonio Fernández de Córdoba, canónigo de gracia de la catedral de Manila, 21 de marzo de 1781. "Testimonio", fols. 54v-55.

20 Ibídem. Declaración jurada de fray José de Santa Orocia, procurador general de la provincia de San Nicolás, previa licencia concedida por el vicario provincial de San Nicolás de Tolentino, fray Mamés de San Lamberto, 21 de marzo de 1781. "Testimonio”, fols. 59-60. También fray Ignacio Seares reconoció haber realizado infructuosamente gestiones encaminadas a lograr la admisión de una mestiza en el beaterio de Santa Catalina. "Testimonio", fols. 91-92. 
"que por lo que le da a conocer el púlpito y confesonario, cree habrá muchas que con vivos deseos apetezcan dedicarse a Dios y vivir bajo clausura, lo que dejan de practicar por carecer de conventos en que sean recibidas, y que no contempla perjuicio el más leve a la causa pública en dicha erección y sí ésta conseguirá muchos bienes espirituales". ${ }^{21}$

Así pues, desde la perspectiva de los declarantes, el único inconveniente podría venir de la financiación. Solucionado este problema con la garantía que proporcionaban los recursos económicos de que disponían los mestizos, los frutos de esta obra serían siempre beneficiosos, tanto para la comunidad de mestizos como para el resto de la república.

"Ha oído que muchas han querido retirarse del siglo, y lo han dejado por considerar no han de ser admitidas en ninguna de las dos comunidades que con clausura hay en esta capital; que el confesonario y los ejercicios que dio habrá cosa de cuatro años en el beaterio llamado de la extinguida Compañía, le dieron y dan a entender ser muchas las mestizas que concurrirían religiosas, si su majestad concediese su real permiso para la erección de dicho monasterio". ${ }^{22}$

En cuanto a la capacidad de los mestizos para recaudar los fondos precisos, todos los declarantes coincidían en que fácilmente reunirían no sólo lo necesario, sino aún más, porque "a ellos solos van a parar la mayor parte de los fondos que hay en esta capital". ${ }^{23}$ La fundación que pretendían no debía recurrir a recoger limosnas, así no se perjudicaría a otras obras que se mantenían de la generosidad de la sociedad. De esta manera, la erección del nuevo convento sería muy beneficiosa y, por tanto, recomendable.

"que siempre que no pidan limosna, no irrogarán perjuicio alguno, y que cree se adelantará bastante en lo espiritual mediante haber varias entre las precitadas mestizas que aspiran a la vida religiosa, cuyo logro facilitarán siempre que tengan monasterio o convento en que poderse retirar del siglo y se evitarán graves daños que ocasiona a la república el privarles de este beneficio, porque carecen de sangre española". ${ }^{24}$

21 Ibídem. Declaración jurada de fray Manuel de San José, previa licencia de fray Manuel Gutiérrez, vicario provincial, 22 de marzo de 1781. "Testimonio", fols. 82v-83v.

22 Ibídem. Declaración jurada de fray José de Santa Orocia, 21 de marzo de 1781. "Testimonio", fols. 60v-61.

23 Ibídem. Declaración jurada de fray Francisco González, previa licencia de fray José Victoria, provincial de la provincia del Santísimo Nombre de Jesús, 21 de marzo de 1781. "Testimonio", fols. 68v-69v.

24 Ibídem. Declaración jurada de fray Diego Martín, previa licencia de fray Manuel Gutiérrez, Manila, 22 de marzo de 1781. "Testimonio", fols. 77v-78v. 
El expediente con el testimonio de todas las diligencias realizadas sobre este asunto fue remitido al rey, con el parecer favorable de la Audiencia de Manila, en mayo de 1781. Este tribunal, basándose en los informes recogidos, calificaba el proyecto de útil, pero dejaba claro que sería así "siempre que en él se pongan superioras de conocida conducta que puedan desde luego doctrinar en la vida religiosa a las primeras que tomen el hábito". ${ }^{25}$

\section{El asunto en el Consejo de Indias}

El expediente fue estudiado por el fiscal del Consejo en enero de 1783; así se inició un largo proceso, complicado por el fallecimiento del primero de los representantes elegidos por los mestizos para llevar a buen puerto su proyecto. En realidad al Consejo habían llegado tanto el expediente formado en Manila (acompañado por la carta de la Audiencia ya citada) como la concesión de poderes por parte de los mestizos, pero en los más de cuatro años transcurridos desde la firma del mencionado poder, no se había llevado a cabo gestión alguna para satisfacer las pretensiones de los mestizos. De esta forma, el Consejo asumió la opinión de su fiscal, en el sentido de que era preciso informar al representante señalado en segundo lugar, don Julián de Illescas, para que exhibiera el poder que le había sido conferido y decidiera los trámites que procedía seguir en este caso. ${ }^{26}$

El asunto se complicó al informar Illescas al Consejo que no había podido conseguir que la viuda de don José Mendoza le entregara el poder que su esposo tenía para el proyecto del convento. El fiscal entonces aconsejó la intervención de don Pedro Muñoz de la Torre, protector de los Agentes en Indias, al que se informó de los detalles de este asunto.

$\mathrm{El}$ hecho de que el citado protector del cuerpo de agentes se inhibiera en esta cuestión, afirmando que no tenía competencia para intervenir en las testamentarías de los agentes, "ni tampoco como juez de ministros, porque no gozan sueldo aunque se les contemple dependientes del Consejo", contrarió profundamente al fiscal, quien respondió con dureza. Así afirmó que

25 Ibídem. La Audiencia de Manila al rey. Manila, 16 de mayo de 1781. En "Expediente sobre la pretensión de los mestizos sangleyes de Tondo, Binondo y Santa Cruz para que se les permitiese fundar a sus expensas un monasterio de monjas del segundo orden de Santo Domingo, con el título de Santa Rosa de Lima. Años 1782 a 1789".

26 Ibídem. Vista del fiscal del Consejo de Indias, Madrid, 10 de enero de 1783. El Consejo resolvió sumarse al parecer del fiscal en su reunión del 14 de enero de 1783. 
le incumbía por su cargo haber puesto a recaudo los papeles de los negocios de América, para evitar los perjuicios que podían producirse si hubiera algún extravío de documentos. Por otro lado, éste era el procedimiento más rápido para recuperar el poder y para que la petición del gremio de sangleyes continuara su tramitación a manos del segundo representante. Ante esto, "mediante que el señor Muñoz se desentiende de mezclarse en este asunto por los justos motivos que para ello le asistirán, sin duda", estimó el fiscal que el escribano de cámara debía entrevistarse con la viuda y testamentarios del fallecido Mendoza, reconviniéndoles sobre la entrega del poder y demás papeles relativos al asunto. En caso de no lograrse, se averiguaría quién era el juez que conocía en la testamentaría y se le pasarían los oficios correspondientes para lograr el objetivo perseguido. ${ }^{27}$

Con todo, no era éste el único problema al que tenía que darse solución; estaba también la cuestión del dinero que el fallecido había recibido para promover la fundación del convento y el intento de suplantar de la comisión a don Julián de Illescas por el hijo del difunto. Efectivamente, doña María Morillo, viuda de don José Ignacio de Mendoza, elevó al Consejo un memorial en el que informaba de la entrega al oficial mayor de la escribanía de cámara, del poder que le había sido demandado, así como de todo lo demás concerniente al "completo desempeño del predicho encargo", al tiempo que señalaba que éste había sido confiado a su hijo, don José María de Mendoza, oficial del cuerpo de Marina. Esto se había hecho por un motivo especial y con la facultad de delegar la comisión en quien considerase oportuno si sus ocupaciones profesionales le impidieran atenderla personalmente. Sin embargo, habida cuenta de que estaba destinado en Cádiz, nada obstaculizaba el que asumiera la dirección del asunto, por lo que se pedía la devolución del poder y de los restantes documentos entregados. El Consejo de Indias fue contrario a esta maniobra, entendiendo que al haber muerto el primer representante sin haber señalado un sustituto, la comisión recaía en el otro elegido por los mestizos. A éste se le debían entregar los papeles relativos a este negocio, así como las cantidades de dinero enviadas.

En este punto, se sabía que le entregaron a don José Ignacio de Mendoza 3.200 reales de plata de a 16 cuartos cada uno, pero se suponía que se le habían podido confiar otras cantidades y era preciso fiscalizar su uso. De esta forma las cuentas presentadas por la viuda del citado agente

27 Ibídem. Respuesta de don Pedro Muñoz de la Torre, protector de los agentes en Indias, 6 de abril de 1783, y vista del fiscal, Madrid, 30 de mayo de 1783. El Consejo asumió la opinión del fiscal, en su reunión de 2 de junio del mismo año. 
fueron sometidas a la inspección de la contaduría general, antes de ser aprobadas por el Consejo de Indias. ${ }^{28}$ Según constaba en los documentos que estudió la contaduría general, el cargo ascendía a 6.023 reales y 18 maravedís, que le fueron entregados a don José Ignacio de Mendoza por don Jacobo Galván, vecino de Cádiz, a través de su corresponsal y don Casimiro Segismundo Agarino. La data ascendía a 1.662 reales y estaba compuesta de cuatro partidas: 18 reales por el porte del pliego en el que había llegado el poder y varios documentos recibidos en septiembre de 1779; 120 reales pagados al abogado que formó la representación para dicho recurso; 24 reales de dos copias que se sacaron de ella para presentar y remitir; 1.500 reales que se cargaron "por razón de agencia y solicitud de este asunto en los tres años corridos hasta el fallecimiento del citado Mendoza, a 500 en cada uno, inclusos portes de cartas y gastos de escritorio, sacando de alcance contra sus bienes y testamentaría la cantidad de 4.361 reales y 18 maravedís de vellón".

En opinión de la contaduría general, el cargo era correcto y había quedado confirmado por una carta original presentada por don Julián de Illescas ante el Consejo de Indias el 3 de septiembre de 1783, firmada por don Jacobo Galván. Sin embargo, en cuanto a las partidas de data, no encontró nada que las justificara "y antes por el contrario, en concepto de esta oficina, presta suficiente mérito para su repulsa y absoluta exclusión". ${ }^{29}$

Se pretendía justificar que don José Ignacio de Mendoza recibió en septiembre de 1779 el poder y los documentos para realizar la solicitud en nombre de los mestizos de sangley y que efectivamente presentó su demanda, a lo que responderían los 120 reales pagados supuestamente al abogado que hizo la representación y los 24 reales correspondientes a las dos copias hechas. Sin embargo, no había en todo el expediente constancia de haberse realizado trámite alguno, a pesar del tiempo transcurrido. De aquí se deduce no sólo que las partidas de data eran injustificadas, sino también la "culpable omisión" del citado representante. En definitiva, el informe de la contaduría general daba por sentado que éste se había desentendido por completo del encargo que se le había confiado y que por lo tanto las cuentas presentadas no eran correctas. Únicamente admitió como legítimo el abono de 18 reales por el porte del pliego en que llegó el poder y otros documentos rela-

28 Las cuentas fueron presentadas ante el Consejo por doña María Morillo el 9 de diciembre de 1783. El 5 de enero del año siguiente el fiscal informó que debían ser inspeccionadas por la contaduría general, y así lo decidió el Consejo el día 10 del mismo mes.

29 AGI, Filipinas, 1.048. Informe de la contaduría general, 26 de febrero de 1784. 
tivos al mismo asunto. De esta forma, también fue rechazado el cobro de los 1.500 reales que su viuda se había abonado en concepto de "solicitud y agencia" del negocio. Teniendo en cuenta los años transcurridos y que no se había hecho nada por realizar el encargo recibido, sorprende el desparpajo con el que se pretendía cobrar por gestiones que no habían tenido lugar.

También se indicaba en el informe que se debía dar cuenta del resultado de la inspección a don Julián de Illescas, encargándole que solicitara en el juicio de testamentaría de su antecesor Mendoza el cobro de los 6.005 reales y 18 maravedís de vellón que resultaban contra ella y el que "promueva el curso de este retrasado expediente, hasta obtener resolución sobre el punto principal a que se dirige". ${ }^{30} \mathrm{El}$ informe de la contaduría general fue asumido por el fiscal y el Consejo de Indias. Éste, a su vez, resolvió someter a la consideración del fiscal la cuenta presentada por la viuda de Mendoza y la solicitud que hicieron los mestizos de sangley en Manila. ${ }^{31}$ En realidad, a partir del momento en que el nuevo apoderado de los mestizos se hizo cargo del asunto, éste comenzó a moverse. La primera de las gestiones que llevó a cabo está fechada el 20 de agosto de 1784; se trata de una representación elevada al Consejo en la que exponía las razones que justificaban la petición de los mestizos y las características que tendría el convento. Terminaba solicitando la autorización para fundarlo y que se comisionara al gobernador de las islas, o a la persona que se juzgara más apropiada, para señalar el número de religiosas que había de formar la comunidad y se iniciaran las obras de erección del monasterio. Apoyaba su solicitud en los informes favorables de la Audiencia de Manila y del gobernador, así como en la suma reunida por los promotores del convento y en la capacidad de éstos para aportar cuantos fondos fueran precisos.

Esta petición fue informada favorablemente por el fiscal del Consejo quien tomó en consideración los informes contradictorios del arzobispo, del gobernador y de la Audiencia. Con todo, y pese a señalar que "parece que no puede ofrecerse dificultad en conceder la licencia", ya que se había respetado el procedimiento establecido por las leyes, señaló tres cuestiones de indudable importancia relativas a las características de la fundación. La primera de ellas se refiere al hecho de que el convento estuviera reservado en exclusi-

30 Ibídem.

31 Esto sucedía el 22 de mayo de 1784. Poco después, el 27 de julio, se firmó un documento de sustitución en lo referente sólo a pleitos, otorgado por don Julián de Illescas en Antonio Parga y Narciso Francisco Blázquez, procuradores de los reales consejos, y Máximo Fernando Ramo Palomino y José Martínez, procuradores del juzgado de Madrid. 
va a chinas y mestizas, lo que podía acarrear serios inconvenientes en caso de que no hubiera solicitudes de ingreso. A juicio del fiscal, este inconveniente podría eliminarse si se establecía la preferencia de ingreso a favor de chinas y mestizas, pero sin excluir a otras, especialmente españolas. La facultad que se reconocía a las religiosas para recibir sus dotes, legítimas y herencias, y para renunciarlas a favor del convento, es la segunda de las cuestiones en cuya consideración se detuvo el fiscal del Consejo. En este punto, y sin duda muy influido por las ideas dominantes en la corte, señala que

"esa ilimitada permisión de amortizar bienes puede con el tiempo llegar a ser muy perjudicial al Estado y Real Patrimonio, siendo así que no se debe conceptuar necesaria tal facultad para la subsistencia del monasterio mediante a que se le ha de dotar ahora competentemente de todo, y en adelante se le irán agregando las dotes de las que vayan entrando en él". ${ }^{32}$

La tercera cuestión sobre la que reflexionaba el fiscal es la tutela de los padres dominicos. En este punto era preciso, si se quería respetar la voluntad de los mestizos, recabar la aceptación formal de la orden a través de un documento firmado por el provincial de Santo Domingo de las islas. Pese a ello, debido sin duda al ambiente que se respiraba en la corte en estos años, el fiscal señala que "acaso sería más conveniente quedasen sujetas las religiosas inmediatamente a la jurisdicción ordinaria del prelado diocesano". ${ }^{33}$ En definitiva, la opinión del fiscal era que estos particulares exigían "previo y más detenido examen, para precaver mayores inconvenientes en lo sucesivo". Por ello, debían ser tomados en cuenta tanto por el gobernador como por la Audiencia de las islas antes de acordar lo más conveniente en el tema de la fundación que se pretendía establecer. Descendiendo ya a cuestiones más concretas, el fiscal indicó que se debía proceder a realizar el plano del convento y a determinar el número de religiosas que acogería, así como la cuantía de las dotes y "todo lo demás conducente a la perfección del establecimiento". De todo ello habría de informarse al Consejo, sin poner en ejecución nada, en tanto se librara la real cédula autorizando la fundación.

El Consejo de Indias asumió el informe del fiscal, al que únicamente añadió la conveniencia de que se señalara también la cantidad de dinero necesaria para la subsistencia de las religiosas. La real cédula correspon-

32 AGI, Filipinas, 1048. Vista del fiscal del Consejo, 28 de noviembre de 1784.

33 Sobre la política secularizadora y las relaciones entre obispos y órdenes religiosas en Filipinas en el siglo XVIII, véase Manchado López, M.: Conflictos Iglesia-Estado en el Extremo Oriente Ibérico. Filipinas (1767-1787), Murcia, 1994. 
diente fue firmada en Madrid, el 19 de diciembre de 1784 y llegó a Filipinas en la fragata "San José" tres años más tarde.

\section{La lenta cristalización del proyecto}

En Manila los trámites administrativos se fueron complicando; el fiscal de la Audiencia consideró que, puesto que se trataba de una fundación eclesiástica, era necesario pedir parecer al arzobispo, a quien se debía remitir todo el expediente. También se debía pedir al apoderado de los mestizos que en el plazo de ocho días presentara ante la Audiencia el plan del nuevo convento, sobre el que el metropolitano expondría su opinión. ${ }^{34}$ Pero el asunto sufrió una nueva demora, a la que no debió ser ajena la mala salud del arzobispo y los muchos problemas a que tuvo que hacer frente como consecuencia de sus difíciles relaciones con las corporaciones religiosas de las islas. Lo cierto es que a don Basilio Sancho le llegó la muerte el 12 de diciembre de 1787, y nada se había adelantado en este asunto. Tal circunstancia hizo que fueran el deán y el cabildo catedral de Manila, que gobernaba la diócesis en sede vacante, los encargados de dar su parecer sobre el proyectado convento. En este sentido, su opinión no difirió de la expresada años atrás por el metropolitano y prueba de la poca importancia que daban al asunto es que su informe no pudo ser más lacónico ni contundente: "halló no ser necesaria la erección de dicho monasterio, pues para que los que quieran tomar semejante estado pueden valerse de los medios que las leyes de estos reinos les suministran". ${ }^{35}$

El expediente formado sobre el tema del convento, incluido el parecer del deán y cabildo catedral, fue entregado al apoderado de los mestizos. ${ }^{36}$

34 AGI, Filipinas, 1048. Vista del fiscal de la Audiencia de Manila, Manila, 13 de agosto de 1787. El informe del fiscal fue asumido por el real acuerdo del 17 de agosto; el mismo día se pasó el expediente al arzobispo.

35 Ibídem. Informe del deán y cabildo catedral de Manila, 20 de febrero de 1788. Los firmantes fueron: los doctores José Tomás Quesada, Ignacio Salamanca, Raimundo de Mijares y José Patricio Molina, el bachiller Juan Prudencio Gómez, Francisco Durana y Domingo José Santelises.

36 Ibídem. El apoderado de los mestizos era el bachiller don Casimiro de los Santos, clérigo presbítero del arzobispado. Testimonio del poder otorgado a su favor por los alcaldes de los gremios de mestizos de los pueblos de Tondo, Binondo y Santa Cruz: el capitán don Francisco Bazon, don Vicente Sixto y don José de los Reyes. Este poder, "tan cumplido que por falta de él no ha de dejar cosa alguna por obrar en cuanto se ofreciere", fue otorgado en Manila el 12 de agosto de 1786. En este mismo legajo se encuentra el testimonio de la sustitución del poder general, otorgado por el bachiller don Casimiro de los Santos a favor de fray Bernardo Javier de las Alas, para que actuara en los pleitos a fin de obtener la licencia para la fundación, fechado en Tondo el 30 de julio de 1787. 
Éste redactó un prolijo memorial en el que intentaba dejar bien asentada la voluntad real favorable a la fundación y lo "extemporáneo" del informe anterior. Efectivamente, en su opinión la real cédula de 19 de diciembre de 1784 ya manifestaba la buena disposición del soberano, puesto que en ella se ordenaba proseguir los trámites, a cuya conclusión quedaba supeditada la aprobación expresa y definitiva del convento. En este estado de cosas, sólo incumbía a la autoridad eclesiástica dar su parecer en lo relativo a aspectos concretos de la fundación, pero en modo alguno sobre la pertinencia o no de ésta, cuestión sobre la que ya se había pronunciado el arzobispo en su momento. En este sentido, era cierto que el metropolitano fallecido se había manifestado contrario al convento, pero, a juicio del apoderado de los mestizos, este informe ya había sido considerado por el monarca y no era lógico suponer que esperara una nueva opinión sobre el mismo asunto.

Más energía dedicó al redundante informe del deán y del cabildo catedral, ya que eran varios los aspectos que consideró necesario contestar. En primer lugar, convenía dejar claro que la fundación de un nuevo convento era una necesidad urgente y el único camino para que las mestizas ingresaran en la vida religiosa. Por otra parte, los reyes mostraban una gran preocupación por el fomento de la educación virtuosa de las mujeres y adoptaban las medidas precisas para ello, entre las que se contaba la concesión de licencias para la erección de monasterios. De esta manera, y aunque no querían que estos centros proliferaran, su celo religioso les llevaba a preferir que hubiera de más que de menos, siempre que quedara acreditada su utilidad o necesidad, circunstancias que concurrían en este caso. Un aspecto muy interesante de su exposición es la defensa que realiza de las cualidades espirituales de las mujeres mestizas, cuestionadas por quienes sumaban a los demás inconvenientes el de su supuesta incapacidad para llevar una vida de perfección religiosa:

"pero en esto se hace un notorio agravio e injuria a las de esta nación, y aun a Dios, pues Su Majestad es el que en estos asuntos hace toda la costa; llenos están los libros y el cielo de santos simplicísimos e ignorantísimos de la prudencia y ciencia del mundo, y sin ella no sólo eran perfectísimos solitarios y monjes, sino obispos y ministros de millares de monjes sapientísimos". ${ }^{37}$

37 Ibídem. Fray Bernardo Javier de las Alas, procurador de causas de los de número de la Audiencia de Manila, a la Audiencia, s.f. 
La habilidad y la eficacia con que se desenvolvían las mestizas en sus quehaceres cotidianos era, además, buen modelo de la ejemplaridad con que podían vivir su existencia retirada en el claustro:

"Si por el obrar en lo humano se arguye el proceder en lo divino, nadie negará en las mestizas el aventajado discurso que tienen para sus adelantamientos, subsistencia, gobierno económico de sus causas, crianza y educación de sus hijos en lo moral y político, y especialmente en el retiro dentro de sus casas". ${ }^{38}$

Por otra parte, los criterios por los que se medía la necesidad de las comunidades monásticas masculinas y femeninas eran muy distintos, porque eran diferentes los fines que perseguían. En el caso de las segundas, su utilidad derivaba del bien espiritual que obtenían las monjas de la vida contemplativa y la mortificación, "y la necesidad es que esta abstración del mundo y negación de sí misma no se puede conseguir por no haber monasterio en que profesar esta vida". Así pues, según insiste el apoderado de los mestizos, la obra era necesaria, buena, y en absoluto onerosa. Debía llevarse a cabo además conforme a lo planeado por los propios mestizos, es decir, como una fundación dependiente no del obispo, sino de los superiores de Santo Domingo. En este punto contradice expresamente lo sugerido por el fiscal del Consejo de Indias y la cuestión no es baladí. En Filipinas aún no se habían olvidado los enfrentamientos entre el arzobispo y los superiores de las órdenes religiosas por razones de jurisdiscción y cualquier iniciativa susceptible de menoscabar la autoridad diocesana era vista con enorme recelo.

Sin embargo, no eran éstos los únicos trámites que la real cédula de 1784 ordenaba y, para darle el debido cumplimiento, dispuso el real acuerdo que se pidiera al apoderado presentara el plano del convento y especificara el dinero con que se contaba, el número de religiosas que ingresarían, la cuantía de las dotes y los fondos necesarios para su subsistencia. ${ }^{39}$ Además, el expediente completo debía ser remitido al provincial de Santo Domingo para que manifestara la voluntad de aceptar bajo su tutela el nuevo convento ${ }^{40}$. Para realizar estas diligencias fue comisionado el oidor semanero don Manuel del Castillo y Negrete, quien el 3 de mayo de 1788 recibió el juramento de los dos arquitectos encargados de realizar los pla-

38 Ibídem.

39 El real acuerdo se reunió el 17 de abril de 1788.

40 AGI, Filipinas, 1048. El padre provincial, fray Nicolás de Cora, manifestó la disposición de su orden de hacerse cargo del convento, "siempre que sea del real agrado y venga con las licencias necesarias". Manila, 26 de agosto de 1788. 
nos: don Domingo de la Cruz González, nombrado arquitecto de oficio y don Juan Bautista Nieto, vecino de Binondo, escogido por los mestizos y aceptado por el oidor comisionado "respecto ser arquitecto conocido". ${ }^{41}$

\section{La financiación del convento}

Uno de los aspectos más importantes de la fundación era precisamente el económico, ya que si no se demostraba la disponibilidad de los fondos precisos para la erección del convento y el digno mantenimiento de las religiosas, el proyecto quedaría frustrado. De ahí que, cuando el real acuerdo pidió la justificación del dinero reunido por los mestizos, éstos se esforzaran en presentar una suma de pesos suficiente. De esta forma, entre los meses de mayo y junio de 1788 se registraron cuatro escrituras de donación y dos declaraciones jurídicas referentes a sendos legados, todas ellas a favor del proyectado convento para mestizas. En cuanto a los legados, alcanzaba cada uno la cifra de cinco mil pesos; debían destinarse a la fábrica del convento y al mantenimiento de las religiosas y respondían a la voluntad expresada por dos benefactoras en sus respectivos testamentos. En ambos casos, se señalaba un plazo de tiempo en el que la fundación debía realizarse; transcurrido éste, si no había tenido lugar o si el "juicio de hombres prudentes" era que el convento no llegara a establecerse, los legados debían reintegrarse a los bienes de las testadoras. ${ }^{42}$

Las cuatro donaciones procedían de miembros de la misma familia, a la que también había pertenecido una de las creadoras de un legado a favor del convento. Se trata de don Antonio Tuazon, teniente coronel de los rea-

41 El proyecto de la obra, que Díaz-Trechuelo atribuye básicamente a Domingo de la Cruz González, consta de la planta del convento y del alzado de la fachada principal del edificio. Las dependencias de las monjas se disponen en torno a un patio interior, aprovechando quizás una casa ya existente. En el plano se refleja un amplio espacio vacío que la citada autora interpreta como reservado a la huerta. Este plano se encuentra en AGI, Mapas y Planos, Filipinas, 179. Es reproducido por la doctora Díaz-Trechuelo, en Arquitectura..., pág. 279. El plano iba acompañado de una relación valorada de los materiales, que se conserva en AGI, Filipinas, 1048. El arquitecto designado por la Audiencia, capitán Domingo González de la Cruz, fue el encargado de dirigir en 1781 la restauración de la iglesia de Binondo, "que ha quedado tan hermosa que no se puede desear más", trabajo por el que no quiso percibir salario alguno. AGI, Filipinas, 652. Testimonio literal de la santa visita de los pueblos extramuros del arzobispado de Manila, fols. 56-56v.

42 AGI, Filipinas, 1048. Se trata de doña Justa Leonor Zaballa, esposa de don Antonio Tuazon, teniente coronel de los reales ejércitos y coronel agregado al batallón del Príncipe, y de doña Francisca de Vera. Las declaraciones jurídicas en que se hace constar la existencia de dichos legados están firmadas: la primera por su esposo, en Binondo, a 26 de mayo de 1788 y la segunda, por la hija, doña Ana de los Ángeles, en Manila el 21 de junio del mismo año. 
les ejércitos y coronel agregado al batallón del Real Príncipe, y de sus tres hijas. El origen de la donación de don Antonio estaba en el voto hecho a Dios en el año 1786 de entregar 25.000 pesos al convento de mestizas para la manutención de sus religiosas. Ésta era la cantidad que esperaba obtener en beneficios de "la crecida suma de pesos" que había invertido en el navío "San Andrés", cuya pérdida llegó a temerse. Al llegar felizmente el navío al año siguiente separó dicha cantidad de sus bienes para destinarla al fin prometido. Al igual que había hecho su esposa al disponer el legado en favor del convento, también señalaba un plazo de tiempo (en este caso 15 años), transcurrido el cual el dinero debía sumarse al resto de sus bienes y distribuirse conforme a lo estipulado en su testamento. ${ }^{43}$

No es ésta la primera ocasión en la que el nombre de don Antonio Tuazon aparece entre los documentos relativos al convento de mestizas. Efectivamente, en 1782 el gobernador de Filipinas remitió a don José de Gálvez una carta pidiendo el rápido despacho de este asunto. En este documento hablaba de la contribución de 5.500 pesos que don Antonio Tuazon realizó en la última guerra y de sus tres hijas que deseaban ingresar en un convento, deseo que anhelaba ver cumplido su anciano padre antes de morir. ${ }^{44}$ Las tres hijas eran doncellas mayores de veinticinco años y compartían su vocación religiosa. Habían tenido conocimiento de que el expediente relativo al convento de mestizas se encontraba en el trámite de manifestar los fondos con que se contaba para fundarlo y les constaba que éstos no eran suficientes. Por ello habían decidido ayudar a su construcción y mantenimiento donando parte de sus legítimas materna y paterna, "que son de alguna entidad". La donación ascendía a 16.000 pesos y se realizaba con carácter irrevocable, aun en caso de que se produjera su fallecimiento o de que desistieran de su vocación, porque con el resto de sus legítimas tendrían suficiente para mantenerse. ${ }^{45}$

43 En la declaración jurídica que firma en Bacolor, a 26 de mayo de 1788, indica expresamente que la donación que hace es lícita (aunque excedía los 500 maravedís de oro, cantidad máxima fijada para las donaciones entre vivos) por ser para una obra pía y por no alcanzar esta cantidad el tercio de sus bienes ni exceder al quinto de los mismos.

44 AGI, Filipinas, 1048. El gobernador de Filipinas, don José Basco y Vargas a don José de Gálvez. Manila, 13 de junio de 1782. Esta carta fue remitida al Consejo de Indias que, en 7 de mayo de 1784, dispuso su incorporación al expediente del convento.

45 Ibídem. La donación se realizó de la siguiente forma: doña Petrona y doña Eusebia entregaron 6.000 pesos cada una (4.000 de sus legítimas maternas y los 2.000 restantes, de las paternas) y doña Martina, 4.000 pesos (2.000 de su legítima materna y otros 2.000 de la paterna). También se incorpora a esta donación una cláusula temporal, de forma que si no se producía la fundación en el plazo señalado (13 años), el dinero debía serles devuelto, con sus aumentos si los hubiese. En la escritura de donación solicitan a su padre que separe estas cantidades de sus legítimas y las guarde hasta el momento en que se realice la fundación. El documento está fechado en Binondo a 26 de mayo de 1788. 
En el mes de julio del mismo año fue registrada ante notario público otra escritura de donación a favor del convento, esta vez de 1.000 pesos. La donante era doña Juana Apóstol, vecina de Binondo, que deseaba tomar hábito en él. La cantidad estaba destinada a la manutención de las religiosas y sería entregada cuando las obras del convento fueran concluidas y "estando todas las cosas en su formalidad". A estos fondos debían sumarse además 615 pesos procedentes de una colecta organizada entre el gremio de mestizos; la mayor parte de esta cantidad (500 pesos) se había invertido en el comercio con Acapulco, destinándose el resto a sufragar los gastos de la tramitación del expediente ante la Real Audiencia. Éstos eran los recursos económicos para la fundación del convento. Sin embargo, como informó el apoderado de los mestizos al oidor comisionado por la Audiencia, había muchos paisanos y paisanas que habían prometido contribuir económicamente, "luego que vean la ejecución de la fundación". Estas donaciones ascendían a cantidades considerables, pero no fueron especificadas por no multiplicar los trámites y retrasar el curso del expediente.

El proyecto de los mestizos se vio favorecido por la generosidad de algunos particulares, como los arquitectos autores del plano del convento que se comprometieron a no cobrar nada por su trabajo, "atendiendo a ser una obra tan pía y santa". En realidad, ya habían contribuido con algunos reales, pero, como ellos mismos afirmaban: "deseamos con todo anhelo el sacrificarnos más y de más empleando nuestro sudor con todo gusto para esta santa fundación". ${ }^{46}$ Una donación importante fue la realizada por don Casimiro de los Santos, apoderado de los mestizos, quien se obligó "gustosamente" en escritura privada a donar las alhajas y muebles de la iglesia: "que son retablos, imágenes (que están ya prontos), campanas, cáliz, copón y vinajeras, ornamentos de género de los cinco colores que usa la Iglesia, lámpara, cruz y ciriales, y otras cosas menudas". Calculaba que como muy pronto el convento estaría fundado pasados dos años y, por si se producía en este tiempo su muerte, dispuso en su testamento que sus albaceas cumplieran este compromiso ${ }^{47}$ Los mestizos habían resuelto que en el convento se recibieran treinta y tres religiosas de coro y doce legas, de las que sólo las primeras deberían llevar dote (300 pesos), aunque no se excluía la admisión de alguna

46 Ibídem. Declaración de don Domingo de la Cruz González y de don Juan Bautista Nieto. Binondo, 1 de julio de 1788 .

47 Ibídem. Escritura de donación realizada por don Casimiro de los Santos, clérigo presbítero, maestro de ceremonias de la santa iglesia catedral y notario mayor del real y apostólico tribunal de la santa cruzada. Santa Cruz, 28 de julio de 1788. 
aspirante pobre que fuera considerada útil o necesaria para el convento. No obstante, al principio se admitiría sólo el número de monjas que se pudiera mantener con las rentas disponibles; éstas procederían de los réditos del dinero que hubiera sobrado tras la construcción de los edificios, empleado en bienes raíces, gestión de la que ya se estaba ocupando el apoderado.

En definitiva, los fondos disponibles ascendían a 52.000 pesos, de los que debían detraerse los 19.982 de la construcción del convento y la iglesia; quedaban 32.018 pesos líquidos que, puestos a censo al rédito del 5\% anual, producirían unos 1.600 pesos. Los rendimientos podían ser mayores (alcanzando hasta el 8\%), si se empleaban en haciendas o tierras sueltas de labor de buena calidad, pero esto dependía de las tierras que se pudiera comprar y parecía más conveniente realizar los cálculos sobre rendimientos seguros. Los gastos anuales a los que habría que hacer frente ascendían a 638 pesos en concepto de alimento del padre vicario y de un criado, salario de mozos y mandaderos, reparación de los edificios, salario del médico y medicinas, salario de dos sacristanes, aceite, vino para misas y cera. Descontada esta cantidad, restaban 962 pesos, con los que se podrían sustentar dieciséis monjas de coro y legas, a razón de 60 pesos cada una,

“con atención a la baratura del arroz y pescado con que se alimentarán, y de los géneros que se vestirán sin diferencia de unas a otras, porque habrán de usar los mismos alimentos y vestuario; y sin necesidad de que haya criadas que las sirvan, porque ellas mismas podrán servirse. Pero, acaso de considerarse necesario o conveniente que las haya, podrán mantenerse cuatro con la cuota regulada por cada religiosa, reduciendo su número a quince". ${ }^{48}$

\section{Los últimos informes y la resolución real}

El expediente completo pasó a informe del fiscal de la Audiencia de Manila quien se manifestó abiertamente favorable a la fundación del convento y, si bien realizó algunas consideraciones en lo relativo al número de

48 Ibídem. Esta evaluación de los gastos fue realizada por encargo del oidor comisionado por el escribano don Gregorio Buenvecino. Manila, 7 de agosto de 1788. El desglose de los gastos es como sigue: alimento del padre vicario y de un criado, 150 pesos; salario de cuatro mozos y dos mandaderos, 72 pesos; reparaciones de la fábrica material del convento e iglesia, 100 pesos; asistencia del médico, 100 pesos; medicinas, 80 pesos; 12 tinajas de aceite de alumbrar para el servicio del convento e iglesia, 24 pesos; cera de la iglesia y convento, 40 pesos; 24 botellas de vino de misa, 12 pesos; salario de dos sacristanes y munecillos, 60 pesos. No se tuvieron en cuenta los gastos que se ocasionarían por ropa de altar y diversas alhajas y muebles, ya que el apoderado de los mestizos aseguró que todo ello quedaba incluido en la donación que se comprometió a hacer. Tampoco se tomó en consideración la comida para los sirvientes "porque con la que se haga para la comunidad habrá para todos". 
monjas, no encontró argumento alguno que justificara la más mínima reserva sobre el proyecto. Así, estimó que la documentación incluida en el expediente dejaba "abundantísimamente justificada la necesidad y justas causas capaces de inclinar el ánimo del Rey para que se digne conceder su permiso". En este punto, consideró sin fundamento las opiniones en contra emitidas por el arzobispo difunto y por el deán y cabildo catedral; el hecho de que las mestizas no tuvieran convento para dedicarse a la vida contemplativa era para el fiscal una causa "justísima y urgentísima". En sus palabras hay una embozada crítica a la actitud adoptada por la mencionada jerarquía eclesiástica, que parecía minimizar un problema cuya importancia era evidente:

\footnotetext{
"en verdad que no es la salud espiritual de estas mujeres de tan poco momento, para negarles por proposiciones no fundadas el asilo que solicitan para dedicarse a vida contemplativa y religiosa, cuando no tienen otro alguno en estas islas en que puedan ser recibidas". ${ }^{4}$
}

El fiscal en su informe también tomó en consideración el dinero de que disponían los mestizos, así como el plan económico presentado y el progresivo incremento del número de religiosas, en función del aumento de las rentas. En nada de ello encontró qué proponer, por acomodarse a lo que se observaba en otras fundaciones de la misma naturaleza. Únicamente señaló que el número de 33 religiosas de coro y 12 legas era "bastante excesivo, y con particularidad si se admiten también criadas seculares, como suele verificarse en los conventos que hay en España de la misma orden". Por ello, sugería la reducción de su número a una tercera o cuarta parte menos, "para que de este modo pudiesen mantenerse con alguna más comodidad las restantes"..$^{50}$ En definitiva, estimó que la Audiencia debía atender a la fundación del convento y que éste debía reunir las características recogidas en el expediente; es decir, que fuese sólo para mestizas, que se mantuviera de sus propios recursos y que su construcción se adecuara al plan ya presentado. En cuanto al dinero que sobrara, se emplearía en comprar haciendas que sirvieran de dotación perpetua y, en el caso de no hallarse éstas de momento, se pondría el dinero a rédito de un 5\%. Sólo se admitirían inicialmente las monjas que las rentas pudieran sostener y su número podría incrementarse al mismo ritmo que éstas, hasta alcanzar el número de 33 monjas de coro y 12 legas, o al número que fijara el real acuerdo, sin

49 Ibídem. Vista del fiscal de la Audiencia de Manila. Manila, 25 de septiembre de 1788.

50 Ibídem. 
excederlo nunca. En todo caso, siempre que se quisiera aumentar el número de religiosas se debería informar a la Real Audiencia a fin de recabar su aprobación. Este tribunal, por lo demás, tendría que aprobar la cuantía de las dotes y el que se invirtieran del mismo modo que el dinero de la fundación, para que con su producto se incrementaran los fondos para el mantenimiento de las monjas; también le correspondería dar el visto bueno a la aceptación sin dote de algunas aspirantes pobres.

De esta forma, todos los trámites ordenados por la real cédula de 1784 fueron cumplidos y de ello dio cuenta la Audiencia con una carta en la que exponía su oposición al nuevo convento. Este documento contravenía uno anterior en el que el mismo tribunal había informado de modo favorable el proyecto de los mestizos ${ }^{51}$ Este radical cambio de opinión se justificaba por tres motivos: la insuficiencia de los fondos reunidos, considerar innecesario el convento y los perjuicios que a la sociedad y al Estado podría causar. En realidad esto suponía echar por tierra todo lo conseguido hasta entonces, en un momento en el que la aprobación real parecía inminente. Esto era así por cuanto las consideraciones de la Audiencia de Manila habrían de pesar en la corte y más aún cuando abundaban en lo expuesto por el fiscal del Consejo en su último informe.

Respecto al primer inconveniente señalado, los 52.000 pesos disponibles eran considerados insuficientes, ya que 20.000 eran necesarios para la construcción del convento y con el resto no se podían afrontar los demás gastos; sólo se podría asegurar la subsistencia de 16 religiosas y, además, en los cálculos no se habían tenido en cuenta los gastos que ocasionaría el traslado desde Europa de las religiosas que se harían cargo de la fundación y de la instrucción de las novicias, gastos de los que tenían que responder los promotores del proyecto. A la escasez de fondos se sumaba un hecho de no menor importancia: a juicio de la Audiencia, el convento era innecesario. En este punto, dicho tribunal asumía la opinión expresada antes por el fallecido arzobispo, y repetida por el deán y el cabildo catedral. Realmente no le resultó muy difícil a la Audiencia defender lo contrario a lo que había dicho siete años atrás en un informe que confesaba no haber podido hallar. Así, negó que hubiera un número elevado de mestizas que quisieran profesar como religiosas; sólo esporádicamente una o dos expresaban este deseo $y$, en las fechas en que se remitía el expediente a la corte, la Audiencia sólo conocía el caso de las tres hijas de don Antonio Tuazon. La falta de voca-

51 Ibídem. Declaración jurada de fray Francisco González..., "Testimonio”, fols. 68v-69v. 
ciones entre las mestizas había quedado de manifiesto en los escasos fondos recaudados en la junta que se celebró con este objeto. De ahí que los 615 pesos reunidos fueran una prueba evidente de la total indiferencia con la que el gremio de mestizos veía el asunto, lo que hacía temer que no estuviera garantizada la subsistencia del convento. En este punto, la Audiencia profundizaba más, puesto que no se limitaba a denunciar el poco interés de los mestizos, sino que aseguraba que el proyecto respondía a los intereses particulares del coronel Tuazon y a los manejos de los dominicos. En su opinión, éstos eran los que habían iniciado el proceso, deseosos de tener en las islas un monasterio de religiosas de su orden. De ahí que, quizás a instancias suyas, los mestizos insistieran en que la fundación debía ser de dominicas de la segunda orden y estar bajo la autoridad de los superiores de Santo Domingo. ${ }^{52}$

La pretensión de que se permitiera a las religiosas recibir y entregar al convento herencias y legítimas es otro de los aspectos contemplados con suspicacia por la Audiencia. Este deseo, sobre el que ya había manifestado sus reticencias el fiscal del Consejo, era entendido como una perversión del auténtico espíritu que debía animar la vida retirada de los claustros:

“esta libertad acarrearía con el transcurso del tiempo el trastorno, alteración y ruinas que por iguales concesiones han sufrido muchas familias y provincias. Vuestra Majestad tiene prevenido en sus reales resoluciones, apoyadas en el derecho canónico, no se funden monasterios sin rentas suficientes para mantener sus individuos, ni que de éstos se admitan más de lo que sufran aquéllas, con que teniendo las que basten, sólo el deseo de enriquecerse, de que deben estar muy ajenos y distantes por su general instituto, puede sugerir igual pretensión con conocido perjuicio de las familias y del Estado". 53

Es difícil descubrir cuáles eran las auténticas intenciones de la Audiencia al atacar de esta forma el proyecto, pero lo cierto es que no pudo esgrimir argumentos más eficaces. La falta de liquidez económica era importante, puesto que la corona no autorizaría una fundación gravosa; pero la denuncia de posibles maniobras de las órdenes religiosas en una época en

52 Los dominicos habían intentado infructuosamente años antes la creación de un convento de clausura para mujeres en Manila; los franciscanos entendieron que esta fundación amenazaba la pervivencia del convento de Santa Clara y alegaron impedimentos de orden económico. A esto se sumaron las reticencias de los vecinos, que veían cómo el número de jóvenes españolas se reducía por las profesiones, y temían no tener esposas para sus hijos. Así pues, Felipe IV en real cédula de 16 de febrero de 1635 prohibió la fundación de dicho convento.

53 AGI, Filipinas, 1048. La Audiencia de Manila al rey. Manila, 24 de diciembre de 1788. 
que se las observaba con enorme suspicacia, era un medio mucho más eficaz para detener una iniciativa que no se veía con simpatía. En este punto, es oportuno recordar que ya el fiscal había hecho notar que se debía considerar si no era preferible que el convento estuviera bajo la jurisdicción directa del ordinario "para precaver mayores inconvenientes en lo sucesivo"; y que el apoderado de los mestizos, cumpliendo la voluntad de sus mandantes, había manifestado que no se debía intentar colocar al convento bajo la autoridad del obispo, sino bajo la de los regulares, "quienes han conseguido privilegios para iguales fundaciones, aunque lo contradiga al ordinario, y aunque le pese".${ }^{54}$ La carta de la Audiencia y el expediente al que acompañaba llegaron al Consejo de Indias en mayo de 1789 para luego remitirse a la contaduría general. En septiembre le fue devuelto junto con una nota en la que se explicaba que no era materia sujeta a su inspección puesto que la fundación no gravaba al real erario. De esta forma, no quedaba más que someter de nuevo el asunto a la opinión del fiscal. Su informe tiene fecha de 3 de octubre y en él se muestra contrario a la erección del convento, alegando motivos económicos. Así, haciendo suyas las consideraciones de la Audiencia, estimó que el dinero conseguido no podía garantizar el mantenimiento del convento. De ello había que informar a los mestizos para que, si persistían en su empeño, consiguieran reunir más fondos.

Una cuestión quedaba pendiente y era la solución que se daría a las jóvenes mestizas que quisieran tomar los hábitos y que viesen frustrados sus anhelos al no autorizarse la fundación. El deán y el cabildo catedral de Manila habían indicado que las leyes del reino proporcionaban los medios adecuados para satisfacer sus aspiraciones. Pero, como aseguró el apoderado de los mestizos, no había ley que franqueara a las mestizas las puertas del convento de Santa Clara y del beaterio de Santa Catalina; y, aunque existieran tales leyes, las mestizas no serían admitidas.

El fiscal era muy consciente de que no había remedio a esta situación:

"Sin embargo de que reconoce el fiscal que será muy sensible a las mestizas de sangley que aspiren al estado religioso el no poder llevar a efecto esta santa vocación y recomendable destino, por defecto de convento en que poderlo verificar, no encuentra por ahora arbitrio para el oportuno remedio de este grave inconveniente, por suponerse que el único monasterio y beaterio que hay en aquel archipiélago no permiten admitir en ellos más que a las hijas puras o mestizas de los españoles, y no poderse alterar esto sin el probable riesgo de cooperar indirectamente con ello a que se altere el sosiego de una y otra comunidad y pasen a ser un seminario de disturbios pertur-

54 Ibídem. Informe del deán y del cabildo catedral... 
bativos de la quietud pública, en lugar de ser un relicario de virtudes que edifiquen a aquellos naturales". ${ }^{55}$

El Consejo de Indias asumió el parecer del fiscal y en el mismo sentido se pronunció el monarca en su real cédula de 22 de noviembre de 1789. De esta forma, se negó la autorización alegando la falta de fondos y, aunque se indicaba que si los mestizos persistían en su empeño debían reunir más dinero, no se deducía del documento real que, conseguidos los fondos, la autorización fuera inmediata. ${ }^{56}$

\section{Las causas del fracaso}

Siendo éste un proyecto generalmente bien visto tanto por particulares como por las autoridades a quienes se pidió su parecer, sorprende que quedara frustrado. Las razones que explican el fracaso de este empeño no son claras: el padre Fernández asegura que fue debido a la conjunción de varias, sin entrar en más precisiones. ${ }^{57}$ Ferrando, por su parte, se limita a señalar que todos los trámites fueron cumplidos y que, cuando se esperaba "de un momento a otro su resolución final, y no obstante que sus promovedores, los mestizos, tenían ya preparados 52.000 pesos para la fundación, no tuvo su gestión en esta parte resultados ulteriores". ${ }^{58}$ Otros autores aseguran que fue la falta de recursos económicos lo que frustró este proyecto, y ciertamente ésta fue la razón alegada por el soberano y por su Consejo. Sin embargo, no lo estimó así el fiscal de la Audiencia de Manila, quien no vio impedimento económico alguno que desaconsejara la aprobación del convento. Por otro lado, la Audiencia no se limitó a denunciar la supuesta falta de fondos, sino que aseguró que el convento era innecesario, perjudicial y que ni siquiera el gremio de mestizos estaba interesado en su fundación; todo ello contradecía los informes recogidos en las distintas fases de tramitación del expediente.

La resolución final no fue seguramente ajena a las insinuaciones acerca de los manejos e intereses de una orden religiosa concreta y la posibili-

55 Ibídem. Informe del fiscal del Consejo de Indias. Madrid, 3 de octubre de 1789.

56 Ibídem. La vista del Consejo de Indias tuvo lugar el 19 de octubre de 1789. La real cédula fue firmada en San Lorenzo el 22 de noviembre del mismo año.

57 Fernández, P.: Dominicos donde nace el sol. Historia de la Provincia del Santísimo Rosario de Filipinas de la Orden de Predicadores, Barcelona, 1958, pág. 340.

58 Ferrando, J.: Historia de los dominicos en las islas Filipinas y en sus misiones del Japón, China, Tung-Kin y Formosa, Madrid, 1871, T.V, págs. 291-292. 
dad de que surgieran contiendas entre el provincial de los dominicos y el obispo. De hecho, se consideró incluso el colocar al convento bajo la jurisdicción directa del metropolitano. Pero, quizá, tanto el fiscal del Consejo de Indias como el Consejo mismo alegaron insuficiencias económicas para sugerir la denegación de la licencia y esta circunstancia fue considerada suficiente. De esta forma, el asunto fue despachado sin entrar a considerar cuestiones más complejas y delicadas.

Por último, es necesario tener en cuenta otro hecho importante y es la naturaleza de la fundación, en el sentido de que se pretendía que estuviera destinada a las hijas de los mestizos de chino. La afirmación de que éstos carecían de dinero es insostenible, así como el que no existieran suficientes vocaciones religiosas entre sus hijas. Otra cosa distinta es la consideración en que se tenía a este grupo y las ideas, bastante arraigadas entre la sociedad española de las islas, acerca de sus insuficientes cualidades morales y espirituales. Desde esta perspectiva, es más fácil comprender la poca importancia que algunas personalidades eclesiásticas dieron a una fundación de esta naturaleza, ya que donde hay poco que cosechar, poco se pierde no cosechando. En este sentido es llamativo el hecho de que sean precisamente las órdenes religiosas, que estaban más próximas a indios y mestizos, las que apoyen más la fundación del convento; incluso aquéllas que, como los franciscanos, podían verse perjudicadas con el nuevo monasterio.

Desde esta perspectiva, considero que en el hecho de no llegarse a fundar el convento de mestizas influyeron, de alguna forma, las razones ideológicas de las que habla Martínez Cuesta al explicar los motivos del contraste entre la vida contemplativa femenina en Iberoamérica y en Filipinas:

"creo que las raíces más profundas del fenómeno son de orden ideológico. Los prejuicios raciales y el tradicionalismo de la iglesia filipina, alejada de Roma y reconcentrada sobre sí misma, prolongaron hasta el siglo XIX actitudes que el transcurso del tiempo había despojado de su primitiva justificación. A finales del siglo XIX todavía continuaba considerando a los filipinos como católicos infantiles, incapaces de afrontar con éxito los retos de la vida religiosa". ${ }^{59}$

En definitiva, al negar la corona la autorización precisa se impidió a las mestizas satisfacer sus piadosos deseos abrazando el estado religioso, pero también se privó a la comunidad cristiana de las islas de los "muchos bienes espirituales" que algunas voces autorizadas afirmaban serían fruto de la profesión de mestizas.

59 Martínez Cuesta, A.: "Monjas y beatas en Filipinas", en Actas del I Congreso Internacional del monacato femenino en España, Portugal y América, 1492-1992, León, 1993, T.I, págs. 511-520. 